\title{
BMJ Open Improving population health one person at a time? Accountable care organisations: perceptions of population health - a qualitative interview study
}

\author{
Douglas J Noble, ${ }^{1}$ Trisha Greenhalgh, ${ }^{2}$ Lawrence P Casalino ${ }^{1}$
}

To cite: Noble DJ, Greenhalgh T, Casalino LP. Improving population health one person at a time? Accountable care organisations: perceptions of population health-a qualitative interview study. BMJ Open 2014;4:e004665. doi:10.1136/bmjopen-2013004665

- Prepublication history for this paper is available online. To view these files please visit the journal online (http://dx.doi.org/10.1136/ bmjopen-2013-004665).

Received 16 December 2013 Revised 20 March 2014 Accepted 24 March 2014
CrossMark

For numbered affiliations see end of article.

Correspondence to Dr Douglas J Noble; djn2004@med.cornell.edu

\section{ABSTRACT}

Objective: This qualitative interview study explored perceptions of the phrases 'population health', 'public health' and 'community health'.

Setting: Accountable care organisations (ACOs), and public health or similar agencies in different parts of the USA.

Participants: Purposive sample of 29 interviewees at four ACOs, and 10 interviewees at six public health or similar agencies.

Results: Interviewees working for ACOs most often viewed 'population health' as referring to a defined group of their organisation's patients, though a few applied the phrase to people living in a geographical area. In contrast, interviewees working for public health agencies were more likely to consider 'population health' from a geographical perspective.

Conclusions: Conflating geographical population health with the health of ACOs' patients may divert attention and resources away from organisations that use non-medical means to improve the health of geographical populations. As ACOs battle to control costs of their population of patients, it would be more accurate to consider using a more specific phrase, such as 'population of attributed patients', to refer to ACOs' efforts to care for the health of their defined group of patients.

\section{BACKGROUND}

Population health has emerged as a widely used phrase in relation to accountable care organisations (ACOs). ${ }^{1-4}$ At the same time, there has been an increasing focus on population health in general across the US health system since the Affordable Care Act (ACA) was passed in $2010 .^{5}$ Yet, the phrase "population health' appears only four times in the ACA, and is not formally defined. In the Centers for Medicare \& Medicaid Services (CMS) final rule for ACOs the phrase 'population health' refers to the health of Medicare beneficiaries assigned to an $\mathrm{ACO}^{1}$ —often referred to as 'attributed

\section{Strengths and limitations of this study}

- First study we know of to explore perceptions of the phrases 'population health', 'public health' and 'community health' among interviewees in a health service organisation and public health agency.

- Reveals key incongruities in the use of the phrase 'population health' with implications for policy and practice.

- May highlight similar confusions in other countries other than the USA and act as an impetus for further research and consensus building at the country level.

- Interviews carried out by a single researcher, offset by two senior researchers with extensive qualitative research experience advising on research throughout its course and reviewing samples of interviews.

- Dependence on the key contact at the accountable care organisation (ACO) to identify the interviewees that may have had the potential to bias the results; and this was addressed by aiming for a consistent representation of key people.

- Small number of ACOs sampled and when interviewees asked about definitions for phrases their response at that moment in time may have been different had they had time to prepare a response or had they been provided with more context, but there was consistency of main findings across sites and in healthcare organisations it is unlikely that much prior thought is given to definitions of everyday management phrases.

patients' - as opposed to the health of every person living in a defined geographical area.

The meaning of population health has been scrutinised by leading US thinkers in recent years. ${ }^{6-11}$ Again, and somewhat surprisingly, a precise widely agreed definition is lacking. In 2013 the Institute of Medicine and Academy Health sought to make sense of the phrase 'population health'. Both cover the geographical meaning, referring to all the people in a given area, as well as a 
healthcare delivery system view (referring to a group of patients for whom the system is formally accountable). ${ }^{1011}$

ACOs are embryonic in their development, yet they often emerge from mature healthcare delivery systems with a rich stock of organisational knowledge. This gives them high visibility within their local communities and to policy-makers. ${ }^{12}$ Public health agencies, by contrast, struggle for funding ${ }^{13}$ and may not have as prominent a role. Both are clearly trying to address 'population health'.

We therefore sought to understand the perception of 'population health' held by leaders and healthcare professionals at four ACOs, and to compare these perceptions with those held by key people in the public health department and/or a similar organisation in each ACO's area. We focused on two questions. What did the phrases 'population health', 'public health' and 'community health' mean to the interviewees? And, what is the relationship between the ACOs and local public health agencies?

\section{STUDY METHODS}

Four ACOs in three states in different regions of the USA that had a relationship with a public health agency were included in a purposive sample. The nature of the relationship was not defined in detail prior to the site visits, and relied on the ACO key contact claiming that such a relationship existed. A balance of urban, rural and different organisational types of ACOs was sought. The overall design of the study, the selection of the four ACOs, and the development of the semistructured interview instrument were shaped by 30 meetings in person or by phone with health policy experts, and ACO, healthcare and public health leaders. An international steering group met twice by conference call to provide advice. An institutional review board exemption was obtained; the identity of sites and interviewees was protected. Written consent was obtained from each interviewee.

Site visits and qualitative interviews were carried out by DJN between January and May 2013. A semistructured interview approach drawing on methods described by Britten ${ }^{14}$ and Patton ${ }^{15}$ was used. The interviews explored the respondents' perceptions of population health, public health and community health; their priorities for the ACO in these three areas; their perceptions of how the ACO was performing in these areas and, the extent of the ACO's relationships with public health agencies. As little information as possible about the study and questions was given in advance to the ACOs. Interviews were recorded using a digital voice recorder, and were later transcribed.

${ }^{\mathrm{i}}$ In this paper government health departments and other non-profit health organisations, which focus mainly on a geographical area rather than on a specific group of attributed ACO patients, are referred to as 'public health agencies'.
Prior to the visit at each site, one of the ACO leaders was asked to schedule interviews with the ACO's chief executive officer (CEO), medical director, nursing director, senior managers, clinicians, leaders and professionals from the local public health agency, or people who had similar responsibilities.

The analysis used a combination of qualitative methods. To aid data management and gain familiarity, data excerpts were organised onto Excel spreadsheets using a framework analysis. ${ }^{16}$ DJN constructed a thematic framework and identified subthemes in each interview. Subthemes were noted for each site with supporting quotes, and were iterated using the constant comparative method. ${ }^{17}$ Focused re-reading of the interview transcripts was performed within and between each site to identify whether newly noticed subthemes had appeared in earlier interviews. Four case site-specific summaries were produced and the relevant one shared with each ACO. Additionally, 16 key interview transcripts (such as with the ACO CEO or public health director) were reviewed by TG and LPC-8 by each researcher.

\section{STUDY FINDINGS}

Thirty-nine interviews were conducted: 29 from ACOs and 10 from public health agencies. Interviews lasted 21-63 (median 32) minutes. All ACOs were in the Medicare Pioneer or Shared Savings Program. Two had a relationship with the local public health department; at one site the main relationship was with two not-for-profit organisations and, one site had a relationship with a local public health department and a not-for-profit organisation that had a role delivering community health interventions. Table 1 shows background information about each site.

\section{Perceptions of population health}

Overall the most common perception of the phrase 'population health' among those working for ACOs related it to a defined group of patients. Sometimes these were directly described as the ACOs 'attributed' patients or patients that the organisation was at risk for financially, and sometimes as the ACO host organisation's patients more generally. For example, a chief medical officer (CMO) said:

...population health to me is really looking at a particular subset of the entire public health that a given organization has assumed responsibility for, for both a quality as well as a fiduciary role

A CEO at a different ACO, when asked about what population they were referring to in relation to their perception of population health, said:

I think it's all of the attributed lives within our region. And that number is growing. You know in the [ACO] we began with Medicare, but quickly we had a commercial 
Table 1 Background information about each site

\begin{tabular}{|c|c|c|c|c|}
\hline Site & 1 & 2 & 3 & 4 \\
\hline Location & Rural & Urban/rural & Urban & Urban/rural \\
\hline $\begin{array}{l}\text { Main components of } \\
\text { organisation }\end{array}$ & $\begin{array}{l}\text { Hospital system } \\
\text { and physician } \\
\text { group }\end{array}$ & $\begin{array}{l}\text { Independent practice } \\
\text { association and hospital } \\
\text { system }\end{array}$ & $\begin{array}{l}\text { Independent practice } \\
\text { association and hospital } \\
\text { system }\end{array}$ & $\begin{array}{l}\text { Integrated } \\
\text { delivery system }\end{array}$ \\
\hline $\begin{array}{l}\text { Attributed Medicare } \\
\text { population size }\end{array}$ & $5000-10000$ & $10000-30000$ & $10000-30000$ & $>30000$ \\
\hline $\begin{array}{l}\text { Approximate population of } \\
\text { main geographical area }\end{array}$ & $<200 k$ & 200k-1 million & $>1$ million & $>1$ million \\
\hline $\begin{array}{l}\text { Number of } A C O \\
\text { interviews }\end{array}$ & 8 & 7 & 6 & 8 \\
\hline $\begin{array}{l}\text { Number of Public health } \\
\text { agency interviews }\end{array}$ & 2 & 3 & 2 & 3 \\
\hline
\end{tabular}

payer group....and now we're looking at the Medicaid populations in an ACO with the State...

At another ACO a family practice physician, who had some of his patients within the ACO contract, said:

Population health to me is...seems to be more of a broader look at how do we take care of a population, it's... at least in my mind, population health management tends to be more of a practical, how do we take care of this population of patients?

When asked about what population he was referring to in the course of his work, he said:

...mine is skewed by my work with the ACO because the population health management is all the patients that we have. So it is...it really is who are my patients? From my own practice standpoint, who are specifically my patients? From an ACO standpoint, who are those attributed to us? are the population we get to take care of, so...

These types of perceptions of population health as a defined group of patients were much more common among interviewees from the ACOs than from the public health agencies.

The second most common perception of the phrase 'population health' was that it referred to all the people living in a geographical area. This view was more common among interviewees from public health agencies. For example, a senior public health official said:

...from the public health side, our notion of population health is really the entire population in an area and so I think that's a fundamental difference. Our denominator is everybody, all residents, and their denominator is enrolled residents

However, a few ACO interviewees also expressed a geographical population health view. For example, an ACO executive at the same site as the last quote (who had previously worked in a health department) said: ...population health is a very broad-based approach to managing the health and cost of care of a population. And you can define that population in many different ways, geographically, those who have self-selected a network of physicians-there are many ways of doing itbut it has more to do with looking broadly at a defined population and managing their cost of care and the quality of care that they receive, and their own health indicators

A senior nurse manager at a different ACO said:

I think population health is anyone in the country. It's the whole population

When the same senior nurse manager was asked about priorities for the ACO in relation to population health, she said:

To improve the health of the recipients within our region

However, when asked how her ACO was addressing the priorities, she said:

I think priorities in population health have been trying to be assessed by the risk stratification tools that have been out with the patients that have presented with high utilization. I also think that through the health risk appraisal that's been developed, we're trying to identify the patient's perception of their own health, get that into the electronic medical record...

In sum, a few ACO interviewees expressed the geographical view of 'population health', and some of these interviewees, at other times in the interview, also implied that 'population health' referred to a group of patients.

Two ACO interviewees at the same site each referred to population health as something to build up one person at a time. For example: 'and it is really one by one, but for a population'. This quote reflects, perhaps, that the traditional unit of intervention for the healthcare delivery system is the individual patient. The epistemological assumption is that knowledge about the 
patient consists of individual data items (eg, biometrics, risk factors, etc) and that knowledge about the population consists of the sum total of individuals. In contrast, the unit of intervention (and the unit for conceptualising health need) in public health agencies is the population or subpopulation.

Another related finding was that on a few occasions ACO interviewees referred to individual patients having 'screenings' rather than the population being 'screened'. This may reflect an underlying desire to deliver a tailored prevention service for each patient, and in that way build population health one at a time. Both of these examples represent a tension between an individual patient and a geographical population perspective. In the former the unit of intervention and the accompanying organisational approach is focused on each patient; in the latter the unit of intervention is the whole population, necessitating a different strategic approach that targets whole geographical populations.

\section{Perceptions of public health and community health}

The most common view of 'public health' was as something that is delivered by the government-for example, by a health department at county or state level. ACO interviewees often listed a wide range of tasks and responsibilities that they perceived for public health. The view of public health as communicable disease control, or health promotion and prevention, was also commonly expressed.

A few, mainly ACO interviewees, suggested that the ACO should partner with public health agencies, for example, in relation to preventive services and health promotion. It was also suggested by a few that ACOs could seek to influence public health policy. For example, a CMO said:

\begin{abstract}
...ACOs need to rely a little bit on public health, and perhaps to help influence some public health policy to make us more successful...in our area, if public health policy changes to put a greater emphasis on creating areas for people to exercise, have active lifestyles...that ultimately is going to be beneficial to the ACO. Those are things I can't do within the ACO alone, so I almost see it more as, you know, we can help to present ideas, we can help to influence, but in some ways, some of the success of the ACO is going to be dependent on some of the public health policies in our community.
\end{abstract}

Despite this extremely cautious acknowledgement of the value of the public health activity locally, this CMO also recognised that the ACO would have limited ability to influence healthy lifestyles in an environment where (for example) healthy food was unavailable.

The term 'community health' was most commonly viewed as referring to the local or neighbourhood level, often implicitly referring to health in the context of small geographical areas. For example, an ACO executive said:
Community health I think is closely allied with both of those [population health and public health] but it's taking it down a level, I think, and it's looking at a particular community or neighborhood or geographic area and looking at ways to improve the health of that community

A few interviewees considered that an ACO's priority should be to understand and connect to community resources for improving health. For example, a nurse case manager, having already mentioned a community wellness centre, said:

...identifying opportunities like that where...could there really be a resource in a community where a resource was absent that could help improve the quality of health for the community?

\section{At a different site a physician said:}

...this idea of working with local communities to specifically identify what the needs and opportunities and resources are in the neighborhood for promoting healthier living, healthier, you know, sort of, living conditions.

\section{Population health, public health and community health}

Many interviewees viewed all three phrases as the same or similar; this was more often the case among public health agency interviewees. For a few of them it appeared to be the case that they had not distinguished between the three phrases before, and reactions during the interviews varied from intrigue to bemusement. Two interviewees at different sites stated that this research had resulted in their considering initiating discussions with colleagues on the definition of population health, and at one site this approach is intended to be used at an initial meeting of multiple healthcare organisations and public health agencies.

\section{Relationships between ACOs and public health agencies}

Each ACO in our sample had a relationship with one or more public health agencies and these took different forms. At one site a new relationship had been established that appeared at least in part to have been strongly influenced by becoming an ACO. At another, becoming an ACO had nothing to do with the relationship with two public health agencies, where relationships had been established some years before becoming an ACO. At the remaining two sites becoming an ACO had either raised the potential for a new relationship, or catalysed existing ones.

At the site where potential for a new relationship had emerged, a senior physician leader said:

...the partnership with the public health agency is relatively new...it seems as though public health agenda and the ACO are going to overlap because today while the ACO has a small subset of the population in that community that we are accountable for, our goal is to grow so that we're taking on more accountability. So, it behooves 
us to work with the public health agency to keep all these other people that are not part of our ACO today healthy because our goal is then to recruit and they would become part of the ACO over time

At the site where a new relationship had been forged following the establishment of the ACO, the main interaction with the public health agency appeared to be mainly related to identifying resources that could be available for patients, for example, referring patients to services run by the public health agency. A nurse coordinator at this site said:

...part of the work towards Accountable Care Organization and population health is that it's going to take everyone, that no one entity can do that alone, and there are a lot of needs and we probably still don't tap all the resources available for all of our patients and we're just beginning to learn to sit with partners and see each other as partners in care for our population or our community

At the site where relationships between the ACO and two public health agencies predated and appeared to be uninfluenced by becoming an ACO, a senior physician leader still recognised the future opportunity between ACOs and public health agencies:

Just by the questions you've asked, it certainly has raised a level of interest on my part of the interface between, you know, public health and the ACOs, and I do think there's great opportunity. I just think the ACOs probably have not matured enough yet. I think we're all still just trying to get on our own legs enough that we're not thinking yet about that next level, but it definitely needs to be in our parking lot, if nothing else

\section{DISCUSSION}

This study revealed that the terms 'population health', 'public health' and 'community health' may have a variety of meanings depending on the context and who is using the phrase. Broadly speaking, many interviewees in ACOs conflated population health with the health of a defined group of patients rather than with the entire population of the geographical locality. The presence of conflicting perceptions not merely within the same ACO but within the same interview, and the admission by a few interviewees that this research study had prompted them to think more deeply about this area in general, suggests that the stock of organisational knowledge specifically about 'population health' in ACOs may still be at an early stage-a finding that is not surprising given that ACOs are still embryological in their development.

In 2003, Dr David Kindig, ${ }^{6}$ a leading US thinker on population health, wrote about the phrase 'population health':

Recently, even in the United States, the term is being more widely used, but often without clarification of its meaning and definition. While this development might be seen as a useful movement in a new and positive direction, increased use without precision of meaning could threaten to render the term more confusing than helpful....

Our case studies support this view, and suggest that a decade later another warning should be sounded about the use of the phrase 'population health' by ACOs and the healthcare delivery system more widely. Using the phrase 'population health' to refer to a defined group of patients is misleading, though well intentioned. It could divert attention from the social determinants of health within geographical areas and to the resources and measures needed to improve geographical population health. This risk is significant, given the underfunding of public health agencies. ${ }^{13}$

The Institute of Medicine Roundtable on Population Health Improvement emphasises that non-medical, social determinants of health are important for improving health. ${ }^{18}$ Healthcare organisations can try to address these social determinants directly and by working with public health agencies and other agencies that create policies for geographically based populations.

A defined group of patients definition of population health could also lead ACOs to conclude (wrongly) that they are addressing all aspects of population health and therefore do not need to form relationships with public health agencies. On the other hand, reflection on the meaning of these terms may lead to enlightenment about the distinction between the role of the ACO (to improve the health of individuals attributed for care) and the role of local public health agencies (to improve the health of the geographical population of the locality), and hence to potentially productive relationships in which each partner plays to their own strengths and values the contribution of the other(s).

It could be useful if people working in ACOs and other healthcare delivery systems had a more accurate term to refer to what they are trying to do. Perhaps they could use the phrase 'population of attributed patients' when discussing the health of their ACO patients. The phrase 'population health' could be reserved for uses that relate to the health of the population in a geographical area. This would make it clear to everyone that these things are different, though there may be overlap, and that ACOs can and should explicitly decide whether and how they will be involved in geographical population health.

The disparity in views of population health between ACOs and public health agencies is not surprising, given their different missions. However, relationships of varying intensity existed between the ACOs and public health agencies. The evolution of these relationships in the future is of considerable interest, as they could contribute to building one of the holy grails of a health system-the bridge between public health agencies and the healthcare delivery system. ${ }^{19}$ 


\section{Organisational and management implications}

Being clear on what is meant by the phrase 'population health' has organisational, management and policy implications. Where relationships are emerging between ACOs and public health agencies, the findings from this study suggest that it might at the very least be useful for the relevant professionals to take time with each other to define what they mean by the phrase 'population health' and what it means for joint projects. Defining perceptions of 'population health' is not just an icebreaker, it could also be an opportunity to foster cooperation between the healthcare delivery system and public health agencies by emphasising a united focus on shared goals.

A longer lasting issue is whether ACOs and public health agencies can learn from each other with regard to population health. Part of this organisational learning is recognising the ethical tension that these two types of organisation will come across, in one form or another, in the course of developing a relationship. Healthcare organisations typically lean towards a deontological worldview that primarily focuses on individual patients and their needs. In contrast public health agencies are more likely to adopt a utilitarian position that seeks to achieve change across the whole geographical population and prioritise the greater good. The interplay between motives driven by commercial gain, and those underpinned by predominantly tax-payer funded public services, map broadly, but not exclusively, to these two worldviews, respectively. Yet, public-private partnerships are possible provided the different organisational positions are clear to those involved.

Tsoukas and Vladimirou ${ }^{20}$ in 2001 in a thesis about organisational learning that draws heavily on the philosophy of Wittgenstein, write:

When our language is crude and unsophisticated, so are our distinctions and the consequent judgments. The more refined our language the finer our distinctions

Varying perceptions of 'population health' may awaken an opportunity for significant cross-organisational learning. And, learning the language to make distinctions between differing perspectives may begin to facilitate organisational learning and joint working between ACOs and public health agencies.

ACOs that do not have a relationship with public health agencies may want to consider this possibility. It may help their patients by utilising public health resources already existing in the community. Contributing strategically to geographical public health interventions, such as flu vaccination that improves herd immunity, may also have health benefits for an ACO's patients and has the potential to reduce costs. Skills and support may also be available for ACOs from public health agencies that have extensive experience in community health needs assessments, robust sampling techniques, aggregating data for health purposes and identifying high-risk groups. Drawing on the findings from this research, table 2 shows five possibilities for how
Table 2 ACOs' relationship with public health agencies

\section{Possible scenarios for ACOs' relationship with} public health agencies

1 ACOs focus mainly on their own patients, with limited contact with public health agencies

2 Spillover effects from ACOs' community benefit programmes bring them into relationship with public health agencies, for example, health education lectures attended by people who are not currently patients, or sporadic health fairs

3 Formal partnership with public health agencies is established to deliver interventions only for the ACO patients, for example, referrals of ACO patients to services run by the public health agency

4 Formal partnership with public health agencies lead to development of a joint strategic plan for interventions for the population of the whole geographical area, for example, a county-wide smoking cessation programme in ACOs, other healthcare establishments, schools, community centres and other locations (with the potential for one shared budget, management and resources)

5 Formal partnership with public health agencies with financial savings due to improved health outcomes being divided among partners, for example, savings from the ACO and the government public health department being reinvested into jointly managed geographically based health improvement interventions ${ }^{21} 22$

$\mathrm{ACO}$, accountable care organisation.

ACOs and public health agencies could begin to learn from each other and interact in practice. It is acknowledged that ACOs may also work with other community partners such as local businesses to improve health, but in this paper we have sought to focus on the relationship between ACOs and public health agencies.

\section{Policy implications}

There are reasons why ACOs may opt not to be involved heavily in relationships with public health agencies. ACOs are not in fact held accountable for the health of geographical populations, and have neither the expertise, the budget, nor the authority to deal with issues such as poverty, education, unsafe neighbourhoods and poor availability of nutritious food. Models of relationships between public health agencies and healthcare delivery systems have been suggested, ${ }^{19} 2{ }^{22}$ but none are in widespread use across the USA. There are also at present no immediate quantifiable incentives for ACOs to form relationships with public health agencies.

\section{CONCLUSION}

The risk of using the phrase 'population health' in a narrow medicalised way for patients, as opposed to referring to the health of all the people who live in a geographical area, is that it may lead policy-makers to assume that by focusing on ACOs they are taking care of population 
health. This may detract from the resources that could be provided to organisations charged with addressing the social determinants of health at a geographical level, such as socioeconomic factors and the physical environment.

ACOs are early in their development, and care must be taken not to expect too much too soon. Being clear on what they can do, and for whom, is critical. The language of policy-makers and healthcare leaders will help create this clarity, and the distinctions between different understandings of 'population health' could contribute to unexplored opportunities for joint working between ACOs and public health agencies.

\section{Author affiliations}

${ }^{1}$ Department of Healthcare Policy and Research, Weill Cornell Medical College, New York, New York, USA

${ }^{2}$ Barts and The London School of Medicine and Dentistry, London, UK

Acknowledgements The international advisory group: Sheila Adam, LPC, Jay Crosson, TG, Sara Shaw, and Jason Sutherland. Bradford Gray for advice throughout the Harkness research project. Jayme Mendelsohn for administrative support.

Contributors DJN led the study, did the primary data analysis and was responsible for drafts of the manuscript. LPC and TG advised on the project throughout its course, reviewed samples of the interviews and contributed to the manuscript.

Funding Support for this research was provided by The Commonwealth Fund, including support for the Harkness Fellowship of DJN.

Disclaimer The views presented here are those of the authors and should not be attributed to The Commonwealth Fund or its directors, officers, or staff.

Competing interests LPC served on the Accountable Care Organisation Task Force for the National Committee on Quality Assurance and serves on the National Advisory Board for Accountable Care News (both positions unpaid).

Provenance and peer review Not commissioned; externally peer reviewed.

Data sharing statement No additional data are available.

Open Access This is an Open Access article distributed in accordance with the Creative Commons Attribution Non Commercial (CC BY-NC 3.0) license, which permits others to distribute, remix, adapt, build upon this work noncommercially, and license their derivative works on different terms, provided the original work is properly cited and the use is non-commercial. See: http:// creativecommons.org/licenses/by-nc/3.0/

\section{REFERENCES}

1. Medicare Program; Medicare Shared Savings Program: accountable care organizations; final rule. Department of Health and Human Services. Vol. 76. No. 212. 2011.

2. Berwick DM. Launching accountable care organizations-the proposed rule for the Medicare Shared Savings Program. N Engl $J$ Med 2011;364:e32.
3. Devore S, Champion RW. Driving population health through accountable care organizations. Health Aff (Millwood) 2011;30: 41-50.

4. Noble DJ, Casalino LP. Can accountable care organizations improve population health?: should they try? JAMA 2013;309:1119-20.

5. Patient Protection and Affordable Care Act, 2010. http://www.gpo. gov/fdsys/pkg/BILLS-111hr3590enr/pdf/BILLS-111hr3590enr.pdf (accessed 11 Apr 2014)

6. Kindig D, Stoddart G. What is population health? Am J Public Health 2003;93:380-3.

7. Kindig DA. Understanding population health terminology. Milbank $Q$ 2007;85:139-61.

8. Jacobson DM, Teutsch S. 'An environmental scan of integrated approaches for defining and measuring total population health by the clinical care system, the government public health system, and stakeholder organizations.' Washington, DC: National Quality Forum, 2012. http://www.qualityforum.org/Publications/2012/06/An Environmental Scan of Integrated Approaches for_Defining and_Measuring_Total_Population_Health.aspx (accessed 11 Apr 2014).

9. Stiefel M, Nolan K. A guide to measuring the triple aim: population health, experience of care, and per capita cost. IHI Innovation Series white paper. Cambridge, Massachusetts: Institute for Healthcare Improvement, 2012.

10. Stoto MA. Population health in the Affordable Care Act era. Academy Health, 2013. http://www.academyhealth.org/files/ AH2013pophealth.pdf (accessed 11 Apr 2014).

11. Committee on quality measures for the healthy people leading health indicators; board on population health and health practice. Toward Quality Measures for Population Health and the Leading Health Indicators. Institute of Medicine, 2013. ISBN 978-0-30928557-5.

12. Small-Picture Approach Flips Medical Economics. New York Times March 12, 2012. http://www.nytimes.com/2012/03/13/health/policy/ with-small-picture-approach-acos-gain-in-health-care.html? pagewanted=all\&_r=0 (accessed $11 \mathrm{Apr} 2014)$.

13. Levi J, Segal LM, St. Laurent R, et al. Investing in America's Health: A state-by-state look at public health funding and key health facts. Trust for America's Health, 2011.

14. Britten N. Qualitative interviews in medical research. BMJ 1995; 311:251-3.

15. Patton MQ. Qualitative research and evaluation methods. 3rd edn. Sage, 2002, ISBN 0761919716, 9780761919711.

16. Ritchie J, Spencer L. Qualitative data analysis for applied policy research. In: Bryman A, Burgess R. eds Analyzing qualitative data. London: Routledge, 1994:173-94.

17. Glaser B. The constant comparative method of qualitative analysis Social Problems 1965;12:436-45.

18. Institute of Medicine Roundtable on Population Health Improvement. Working definition of population health. http://iom.edu/ /media/Files/ Activity\%20Files/PublicHealth/PopulationHealthlmprovementRT/Pop \%20Health\%20RT\%20Population\%20Health\%20Working\% 20Definition.pdf (accessed 11 Apr 2014).

19. Shortell SM. Bridging the divide between health and health care. JAMA 2013;309:1121-2.

20. Tsoukas $\mathrm{H}$, Vladimirou $\mathrm{E}$. What is organizational knowledge? $J$ Manage Study 2001;38:973-93.

21. Magnan S, Fisher E, Kindig D, et al. Achieving accountability for health and health care. Minn Med 2012:95:37-9.

22. Shortell SM. A bold proposal for advancing population health Discussion paper. Washington, DC: Institute of Medicine, 2013. http://www.iom.edu/Global/Perspectives/2013/BoldProposal (accessed 11 Apr 2014). 